INOBIS: Jurnal Inovasi Bisnis dan Manajemen Indonesia

Volume 03, Nomor 04, September 2020

Tifa Noer Amelia

\title{
Evaluation Framework on Start-up Incubator Business Model: What to Ask and How to Employ Data Management Tools (N-Vivo)
}

\author{
Tifa Noer Amelia \\ Perbanas Institute \\ tifanoer@perbanas.id
}

\begin{abstract}
In recent years, developing economies countries such as Indonesia witnessing the growth of the incubator business for digital start-ups. Digital start-up is an early-stage business that requires to maintain its growth supported by the ecosystem. One of a prominent part in the ecosystem is a business incubator. This is descriptive research that aims to construct research question guideline and how to organize the gathered data using tools called Nvivo based on the provided evaluation framework.

Keywords: start-up, incubator, business model, evaluation framework, Nvivo

\section{Introduction}

Business incubators are synonymous with companies that provide facilities for digital-based startups such as working spaces, internet networks, technical devices, mentors and consultants related to managed businesses such as law, finance and other administrative support. Digital start-ups themselves are commonly referred to as tech-start-ups and innovation start-ups. Digital start-ups are start-up companies that take advantage of the sophistication and advancement of technology as well as information systems and in the form of applications that can be accessed by users through devices such as cell phones and computers. The mapped business model is evaluated using a framework that the researcher has compiled and ends with simplification, elimination and combining elements in the evaluation framework to make it more efficient according to the facts that occur in the object of research. The research was conducted using a qualitative approach, using the N-Vivo tool. Verification of the validity of the data used triangulation with experts, interviews, and field analysis. The research method begins with data transcription, provides a code for the data, is linked between codes and the meaning of the model. The study ended with the results of the evaluation and studying the digital start-up incubator evaluation model.
\end{abstract}

\section{Literature review}

Component to be evaluated based on the evaluation framework that consisted of pre, mid and poststage (Amelia, Armanu, Irianto, \& Rofiq, 2017). Pre-entrepreneurial and post-entrepreneurial phases evaluation are important to be in a business model (Lai \& Lin, 2015). Measure post-incubation success also a strong indication of start-up success (Ahmad, 2014). Evaluation framework before and after the incubation program also necessary conducted to see how far an incubator can accommodate start-up in developing their product and to respond to the market in the future (UN, 2004). Business incubation divides the stages of pre-incubation evaluation, incubation process, and post-incubation (Mungila Hillemane Bala, Satyanarayana, \& Chandrashekar, 2019). The information gathered in this business practice can be in form of an interview, seminars, press conference, news, and document assessment. To combine and structure the information, and the analysis tool employs. One of the powerful tools to combine all this kind of file is Nvivo. Nvivo is one of the computer-aided qualitative data analysis software to improve the quality of research. Using Nvivo improve accuracy and precision on the gathered data (Siccama Carolyn \& Penna, 2008). This tool is able to provide extensive map, activity track, code and connecting nodes from various 
INOBIS: Jurnal Inovasi Bisnis dan Manajemen Indonesia

Volume 03, Nomor 04, September 2020

Tifa Noer Amelia

file type. Especially in an entrepreneurship context when the narrative explanation is crucial to find the essence of the information (Kikooma Julius, 2010).

\section{Method}

This research firstly develops a framework that consists of three stages in business incubation, seven topics and twenty-eight criteria to evaluate. But then, after further assessment, the First stage is preincubation, followed by mid-incubation and post-incubation (Amelia et al., 2017). Seven topics are about the sourcing, business ide development, business plan, targeted achievement, implemented the business plan, benchmarking and value creation. On every topic, colliding or criteria with similar explanation are eliminate or merge to build a rigid and stronger definition on each item. Such as human criteria are a combination of intellectual and competence. Finance also combining revenue stream criteria due to its similar definition. Customer segment also covering customer relationship. Public expose is merge in to commercialization and internationalization. Strategy aspect is eliminated. The last is combining searching engine optimization and searching engine marketing. After the elimination and combination process, twenty-one criteria of incubation that can be form an effective and efficient incubator. This component has their own information. A data management tool employs to see the data sufficiency and accuracy in measuring the business practice. Nvivo is one of the prominent tools that has the ability to measure this.

\section{Result}

\section{A. Question guideline}

First stage is Pre-incubation. This is the activity prior to the incubation program that must be fulfill by the incubator. There are seven topics, and each topic has their own recommended question.

1. Physical criteria are tangible assets or wealth that can be physically manifested into something valuable or tangible. So, the recommended question is:

a. Headquarter or main office building of the company.

b. Rented or owned vehicle, office room, and land.

2. Human criteria are all matters relating to the company's human resources, recruitment, placement, transfer, workers compensation, training and performance appraisals. Due to human aspect includes intellectual and competence, so it is also added intelligence in the form of a person's skills, abilities, expertise and insight to generate innovation and creativity. Then, the organization's ability to maintain, develop and create relationships with other parties.

a. Management team education and working experience background.

b. Required and available skill (management team, technical team to mentor).

c. The relation among stakeholders.

3. Finance criteria is a source of company funds that are generally obtained from investors, financial institutions and the founder's money (bootstrapping). Include how to gain financial support and to make a profit.

a. The source of fund for the program.

b. The company ability in making profit.

4. The vision describes where the organization wants to be in the future.

a. Vision statement and how is it correlated to the company's goal.

5. Mission criteria is explained what the organization needs to do at this time.

a. Mission statement and how is it correlated to the company's vision.

6. Value criteria is moral direction for the organization that guides decision-making and sets standards for judging action.

a. Culture of the company (moral, standard, principle). 
7. Goal criteria is targeting the company wants to achieve are usually in the form of descriptions of things the company wants to achieve complete with a time frame for their achievements.

a. Statement of organization purpose.

Second stage is Mid-incubation. This is the activity in the middle of incubation program. This is the organization effort to reach external parties.

8. Customer Segment criteria is the character of the incubator participants according to their business model. Include the way companies work together and maintain relationships with consumers.

a. Map the incubator current customer, potential customer and expected customer.

b. Activity to prepare before the tenant register the program.

c. What facility their tenant gets during and after the incubation program.

9. Value Proposition criteria is advantages that make one incubator different from other incubators.

a. The special offer from this program.

b. The differentiation compared to the other incubator.

10. Channels criteria is a distribution chain that will connect the products and services provided to reach the participants.

a. Program to reach the potential customer.

b. Activity to maintain customer.

c. Exact period for that activity.

11. Key Activity criteria is describing the upstream to downstream processes that the incubation company will undertake at the start-ups it manages.

a. Activity after the recruitment up to the output.

b. Curriculum for the program.

12. Key Partnership criteria is the relationships a company has with other businesses, government entities, or non-consumers that help the business model work.

a. Collaboration opportunity with external party or another relevant partner.

b. Collaboration with government, university or private company if possible.

13. Contribution to Economy criteria is contribution in the form of an increase in economic growth indicators.

a. Whether it has potential for new employment opportunity.

b. Increase in Gross Domestic Product (GDP).

14. Commercialization criteria is recognition of the commercial status of a product.

a. Provide patent and copyright consultation for the product output.

15. Internationalization criteria is exposure by foreign users and investors, building and boosting overseas networks, as well as access to and mobilization of resources from abroad.

a. Provide international collaboration or opportunity for internationally recognized.

16. Execute the implementation of ideas according to results.

a. The ability to accomplished the business target based on the target.

17. Performance criteria is business performance in the model related to the best practice of a process in a similar industry.

a. The competition climate in the industry.

b. Market share position in the industry.

18. Technology criteria is the use of information systems where one activity is related to activities to meet the goals the company wants to achieve with the minimum effort but can produce (productively) as much as possible.

a. Hardware specification.

b. Software update. 


\section{Tifa Noer Amelia}

19. Process criteria is company integration activities related to the control environment, risk assessment, control activities, information and communication, and monitoring.

a. Standard procedures for every transaction.

b. Supervision on every division.

Third stage is Post-incubation. This is the last activity an incubator must be prepare for their tenant. This is related to the post incubation activity that will expose the start-up under their incubation program achieve more recognition.

20. Searching Engine Optimization criteria is optimization of search engines to increase website traffic or user pages in search engines. Include an increase in website visibility through advertisements and paid content.

a. About paid advertisement on their content.

b. About recruitment and program promotion media.

21. Due Diligence criteria is due diligence is the creation of company performance values to comply with applicable legal rules and standards

a. All business-related eligibility, include environmental aspect, legal aspect, administration and external exposure.

b. What criteria a tenant can expose or commercialize their business.

\section{B. To Employ Tool}

Qualitative research needs to measure the validity (accuracy), reliability (reliability) and accuracy (truth) of the data. The accuracy of the data using snowball sampling. Data reliability using matrices and data management tools. The correctness of the data uses triangulation. Feature used from the Nvivo can be adjusted based on the information required by the researcher. Not limited but step by step on using the data management tool can use recommended step below:

1. Install program $\rightarrow$ open page $\rightarrow$ create new project.

The latest product is Nvivo that can be downloaded the trial version for two weeks or paid version for unlimited experience. The link available in https://www.qsrinternational.com/nvivoqualitative-data-analysis-software/home.

2. Insert the file $\rightarrow$ select preferable format.

This is to begin the research project by inserting the available data. Transcripted file can be from MS. Word, the video file can be from YouTube, the audio file can be from recorded interview, and online article can be encrypted using N-Capture feature.

3. Query $\rightarrow$ Text search for each category $\rightarrow$ word tree feature.

This is the step to find the correlation on each category to the designed topic. If the line on word tree construct the topic, so the data are accepted or the topics are well explained. Word cloud also can appear using this step. To see the criteria most to lest talk about.

4. File $\rightarrow$ codes $\rightarrow$ block and right-click the sentence that is related to the node.

This is to provide code on the sentence indicate the criteria. One sentence possible to include on more than two nodes.

5. Explore $\rightarrow$ hierarchy chart from nodes $\rightarrow$ word frequency.

This is the step to see composition of data towards expected information. The output is in form of square chart that show the bigger space is the larger scope of information. Sometime it could be deeper information. 
6. Explore $\rightarrow$ comparison diagram $\rightarrow$ compare files.

Compare data sources using the comparison chart. Per bundling of information can be defined on their ability to fill the required criteria.

7. Explore $\rightarrow$ chart $\rightarrow$ click coding $\rightarrow$ click coding for a file $\rightarrow$ select source.

Source composition will compare the part of each data source on the required criteria. Graph will show how each source relate to each other.

\section{Conclusion}

The question guideline to fill the twenty-one criteria, to form seven topics, and to establish a business incubation phase is a must. Criteria to ask related to the physical, human, finance, vision, mission, value, goal, channels, key activity, key partnership, contribution to economy, commercialization, internationalization, execution, performance, technology, process, searching engine optimization and due diligent criteria. After the data gathering, transcription of the data sources is important, whether audio, video, online article, documents, or direct note during the interview and manage it using Nvivo feature.

\section{References}

Ahmad, J. A. (2014). A mechanisms-driven theory of business incubation. International Journal of Entrepreneurial Behavior \& Research, 20(4), 375-405.doi:10.1108/IJEBR-11-20120133

Amelia, T. N., Armanu, A., Irianto, G., \& Rofiq, A. (2017). Constructing Framework for Business Incubator Benchmarking: for Startup-Tech Company. International Journal of Mechanical Engineering \& Technology, 8(12), 1066-1074. Retrieved from http://www.iaeme.com/ijmet/IJMET_Paper.asp?sno=10096

Kikooma Julius, F. (2010). Using Qualitative Data Analysis Software in a Social Constructionist Study of Entrepreneurship. Qualitative Research Journal, 10(1), 40-51. doi:10.3316/QRJ1001040

Mungila Hillemane Bala, S., Satyanarayana, K., \& Chandrashekar, D. (2019). Technology business incubation for start-up generation: A literature review toward a conceptual framework. International Journal of Entrepreneurial Behavior \& Research, 25(7), 14711493. doi:10.1108/IJEBR-02-2019-0087

Siccama Carolyn, J., \& Penna, S. (2008). Enhancing Validity of a Qualitative Dissertation Research Study by Using NVIVO. Qualitative Research Journal, 8(2), 91-103. doi:10.3316/QRJ0802091

UN. (2004). Promoting Business and Technology Incubation for Improved Competitiveness of Small and Medium-Sized Industries Trough Application of Modern and Efficient Technology. Paper presented at the Economic and Social Commission for Asia and the Pacific, New York. 